\title{
BMJ Open Parents' attitudes as mediators between knowledge and behaviours in unintentional injuries at home of children aged 0-3 in Shanghai, Eastern China: a cross-sectional study
}

Xueqi Ma, ${ }^{1,2}$ Qi Zhang (D) , ${ }^{3}$ Ruo Jiang, ${ }^{1,2}$ Jun Lu, ${ }^{1,2}$ Huiping Wang, ${ }^{4}$ Qinghua Xia, ${ }^{5}$ Jicui Zheng, ${ }^{6}$ Wei Deng, ${ }^{1}$ Fengshui Chang, ${ }^{1,2}$ Xiaohong Li (D) ${ }^{1,2}$

To cite: Ma X, Zhang $Q$, Jiang $R$, et al. Parents' attitudes as mediators between knowledge and behaviours in unintentional injuries at home of children aged $0-3$ in Shanghai, Eastern China: a crosssectional study. BMJ Open 2021;11:e054228. doi:10.1136/ bmjopen-2021-054228

- Prepublication history and additional supplemental material for this paper are available online. To view these files, please visit the journal online (http://dx.doi.org/10.1136/ bmjopen-2021-054228).

Received 08 June 2021 Accepted 01 December 2021

Check for updates

(c) Author(s) (or their employer(s)) 2021. Re-use permitted under CC BY-NC. No commercial re-use. See rights and permissions. Published by BMJ.

For numbered affiliations see end of article.

Correspondence to

Dr Xiaohong Li;

lixh@fudan.edu.cn

\section{ABSTRACT}

Objective Parental behaviours are important in preventing unintentional injury at home among young children. Previous research showed an inconsistent relationship between knowledge and behaviours, indicating that the mechanisms may vary for different behaviours. This study aimed to examine the mediating roles of different attitudes in the mechanism of knowledge acting on different behaviours.

Design Cross-sectional study.

Setting Eastern China.

Participants Participants were recruited using stratified community-based sampling. A total of 488 parents of children aged 0-3 years participated in the study and 476 (97.5\%) valid questionnaires were recovered.

Primary outcome measures Parents' knowledge, attitudes (including injury attribution, preventability and responsibility) and behaviours (including supervision behaviours, risky behaviours and providing a safe home environment).

Results The results of mediation analysis showed that the mediator variables were different for different behaviours and that all associations were positive. Parents' knowledge ( $\beta 0.19,95 \% \mathrm{Cl} 0.13$ to 0.24 ) and attitude of injury attribution ( $\beta 0.37,95 \% \mathrm{Cl} 0.21$ to 0.46 ) were directly associated with risky behaviours. Attitude of preventability was directly associated with parents' supervision behaviour ( $\beta 0.27,95 \% \mathrm{Cl} 0.14$ to 0.40 ). Parents' attitude of preventability mediated the positive association between knowledge, attitudes of injury attribution and responsibility, and supervision behaviours, as well as providing a safe home environment. In addition, the occurrence of child injuries at home was directly associated with home environment $(\beta-0.41,95 \% \mathrm{Cl}-0.82$ to -0.01$)$. Conclusions The current findings confirm that attitudes play varying mediating roles between knowledge and different behaviours. An important recommendation is that parents' attitudes, especially towards preventability and responsibility, need to be considered when health providers develop health education programmes targeted at improving parental supervision behaviours and providing a safe home environment.

\section{Strengths and limitations of this study}

- The use of generalised structural equation model allowed us to explore the role of mediating factors.

- The study dissected parents' attitudes and behaviours to compare the mediating association of different attitudes in different behaviours.

- As we used cross-sectional data, we cannot make causal inferences from the results.

- Social desirability bias could occur easily and parents could deliberately withhold information, especially about their attitudes and behaviours.

Unintentional injury of children is an important public health problem. According to the WHO, injuries are the top three causes of child death in both developing and developed countries. ${ }^{1}$ The top five injuries among children are falls, collisions/squeezes, cuts/ stabs, traffic accidents and burns/scalds, with more than half of all child injuries occurring at home. ${ }^{2}$ There are differences in the incidence of unintentional injuries at home among children of different ages. Road traffic injuries are the most common unintentional injuries among school-aged children, while for children aged $<6$ years home injuries such as asphyxiation, fire and drowning are more common. $^{13}$

Many factors, such as children's characteristics, ${ }^{4}$ inadequate parental supervision, ${ }^{5}$ unsafe home environment ${ }^{6}$ and lack of protective appliances, ${ }^{7}$ contribute to the occurrence of home injuries in children. Home environment factors are significantly associated with occurrence of unintentional injuries in children, ${ }^{8-10}$ and creating a safe home environment can reduce unintentional injuries among children. Young children's bodies and awareness are not yet mature, and 
this is especially true for infants and toddlers; however, parents, as primary guardians, can effectively prevent the occurrence of injuries in children. ${ }^{112}$ How to provide a safe home environment and improve parental behaviour has become the focus of research on preventing unintentional home injuries in children.

While factors influencing home injuries in children have been examined, some questions remain. The relationship between knowledge and behaviour, for example, is inconsistent. Several studies have shown that better knowledge leads to safer behaviours ${ }^{13}$; however, other studies have found that parents with knowledge do not have good behaviour. ${ }^{14}$ Therefore, researchers have highlighted the importance of attitude. Azar $e t a l^{15}$ suggested that parents develop an attitude of preventability alongside an understanding that unintentional injuries do not occur by change, in an attempt to improve supervision behaviour. Some studies have found that parents' attitudes are related to their behaviours ${ }^{16}$ while others have found no such relationship, ${ }^{17}$ showing that further studies are needed to analyse the influence of attitudes on different behaviours.

In addition, most previous studies focused on schoolaged children. Due to the different influencing factors of unintentional injury in children of different ages, analysis needs to be carried out by age group. Only a few studies are focused on children aged 0-3 years, and little is known about the relationship between parental attitudes and unintentional injuries of children aged 0-3 in developing countries. Therefore, it is necessary to carry out a study on unintentional injuries at home for children aged 0-3 years.

Based on the Haddon model,${ }^{18}$ in terms of unintentional injuries in young children, the most important factors include home and social environment. In terms of social environment, it is important to improve parents' supervision behaviour and avoid risky behaviour to prevent unintentional injuries at home. In addition, based on the KAB (knowledge, attitude and behaviour) model, behaviours are influenced by knowledge and attitudes. ${ }^{19}$ Developed as a health promotion model, the KAB model explains that a person's knowledge directly affects their attitude and indirectly affects behaviour through their attitude. ${ }^{20}$

This study aimed to examine the different mediating effects of attitudes on behaviours and their mechanisms, providing information for the development of targeted health education interventions.

\section{METHODS}

\section{Study design, setting and period}

We performed a cross-sectional survey of parents of children aged 0-3years old from September to November in 2018 at the department of physical examination for children of community health centres in Jiading District, Shanghai, China.

This study was conducted in the central area of Jiading District, located in the northwest of Shanghai and covering an area of $464.2 \mathrm{~km}^{2}$. The per capita GDP (gross domestic product) of Shanghai in 2017 was $¥ 124536$, ranking second among 31 provinces in mainland China, while the GDP of the whole mainland China was $¥ 59600 .{ }^{21}$ Jiading’s per capita GDP was ¥104423, ranking sixth among the 16 districts in Shanghai. The local resident population of Jiading was 1588900 . The central area of Jiading District, with about 30000 children aged $0-3$, was selected as the sample site, ${ }^{22}$ with two community health centres in the central area. According to the National Guideline of Basic Childhood Health Care, all children aged 0-3 should be registered at one local community health centre, where they are provided regular physical examinations at no cost.

\section{Participants and data collection}

The respondents were fathers or mothers of children aged 0-3 who accompanied their children to Jiading Town and Juyuan New Town community health centres for regular physical examination. Parents who were unable to participate in the face-to-face interview, whose children were disabled or not singleton, or were unwilling to sign an informed consent form were excluded.

Considering that this study was conducted in the central area of Jiading District, we assumed that there would be no significant differences between different residential quarter households. Furthermore, we hypothesised that the age of the child was an important factor associated with parents' knowledge, attitudes and behaviours, as well as the child's injuries. Subsequently, we adopted a stratified sampling method based on children's age. According to the modelling requirements of generalised structural equation model (GSEM), at least 150 children of each age group were required, with a total of at least 450 parents. ${ }^{23}$ We issued 488 questionnaires, and 476 valid questionnaires were recovered, with the response rate reaching $97.5 \%$. The parents of 12 children were excluded for the following reasons: (1) 6 children went to the community health centre without being accompanied by their parents; and (2) 6 children's parents refused to participate. A total of 476 children were evenly distributed according to age groups and community health centres, including 168 (35.29\%) children aged 0-1, 151 (31.72\%) children aged 1-2, and 157 (32.98\%) children aged 2-3.

The investigators, who were all graduate students of Fudan University, were trained prior to the start of the investigation. We communicated with the investigated community health centres to obtain on-site support and organisational coordination. Before starting the interview, the child healthcare doctor of the community health centre determined whether the child's parents met the eligibility criteria based on children's and parents' basic information. All survey data were completed through face-to-face interviews by the investigators using a structured questionnaire about parental knowledge, attitudes and behaviours. During the investigation process, quality control personnel were set up to check the completed questionnaires. 
Before the investigation, a pilot study, including 30 parents, was conducted to obtain information that might be useful for the improvement of the investigation. After the pilot survey, the questionnaire and survey plan were modified and improved.

Health providers were involved throughout the study process. There were four focus group discussions before the questionnaire was formed. There were 5-10 providers in each discussion. The providers consisted of paediatricians and nurses from hospital and community health centres and public health experts from community health centres and the Center for Disease Control and Prevention. All discussions were facilitated by researchers from Fudan University. In addition, the questionnaire was verified by 23 children's clinical, nursing and healthcare experts, public health experts, and primary healthcare experts with rich practical experience and theoretical attainments from community health centres, the Center for Disease Control and Prevention, and maternal and child healthcare hospitals.

\section{Unintentional injuries at home}

Injuries at home refer to injuries sustained by children in the home environment. An injury is defined as an event that meets any of the following criteria by the International Classification of Diseases, 10th edition: (1) the child received medical treatment by a doctor or another medical professional after being injured; (2) the child received first aid, such as medication, massage or a hot compress, from a family member, teacher or other nonmedical personnel after being injured; and (3) the child was unable to attend school or participate in other activities, was bedridden or was required to rest for more than half a day after the injury. ${ }^{24}$

\section{Model framework and measurements}

Based on the KAB model, knowledge is associated with behaviours through attitudes. With better knowledge, parents can develop better attitudes, which leads to better behaviours. Thus, 'knowledge' is the independent variable, 'behaviour' is the outcome variable and 'attitude' is the mediating variable.
Based on literature on unintentional injury in young children, including literature on basic knowledge and behaviours of parents and children about unintentional injury prevention, ${ }^{25-27}$ literature on parents' attitudes related to child unintentional injury, ${ }^{28}$ as well as literature on theories of personality, including locus of control ${ }^{29}$ and the Big Five model, ${ }^{30}$ we divided 'behaviours' into 'supervision behaviour', 'risky behaviour' and 'providing a safe home environment', while 'attitudes' were divided into 'attribution', 'preventability' and 'responsibility'. In addition, we conducted focus group discussions. The themes included the following: (1) In your opinion, what do you think are serious or common unintentional injuries among young children? (2) What do you believe are the causes of unintentional injury of young children? (3) What do you think can be done to reduce child unintentional injury in terms of parental knowledge, attitudes and behaviours? Finally, this study proposed a framework as shown in figure 1 . The measurements were as follows.

\section{Parents' knowledge}

Parents' knowledge referred to basic knowledge which the parents should possess related to unintentional injury and safety of the child. In this study, this was examined using eight questions covering child injuries such as suffocation, burns, falls and drowning at home. There were three response choices for each question (true, false and unknown). The questions were scored 1 and 0 for correct and incorrect answers, respectively (see online supplemental file).

\section{Parents' attitudes}

There were one or two questions for each dimension regarding parents' attitudes, including parents' attitudes of injury attribution, responsibility and preventability. Responses were recorded using a 4-point Likert scale: $1=$ strongly disagree, $2=$ disagree, $3=$ agree and $4=$ strongly agree. Some items were positively scored and some were reverse-scored (see online supplemental file).

Parents' attitudes about injury attribution were assessed with the following statement: 'It is due to bad luck that children get unintentionally injured'. This was

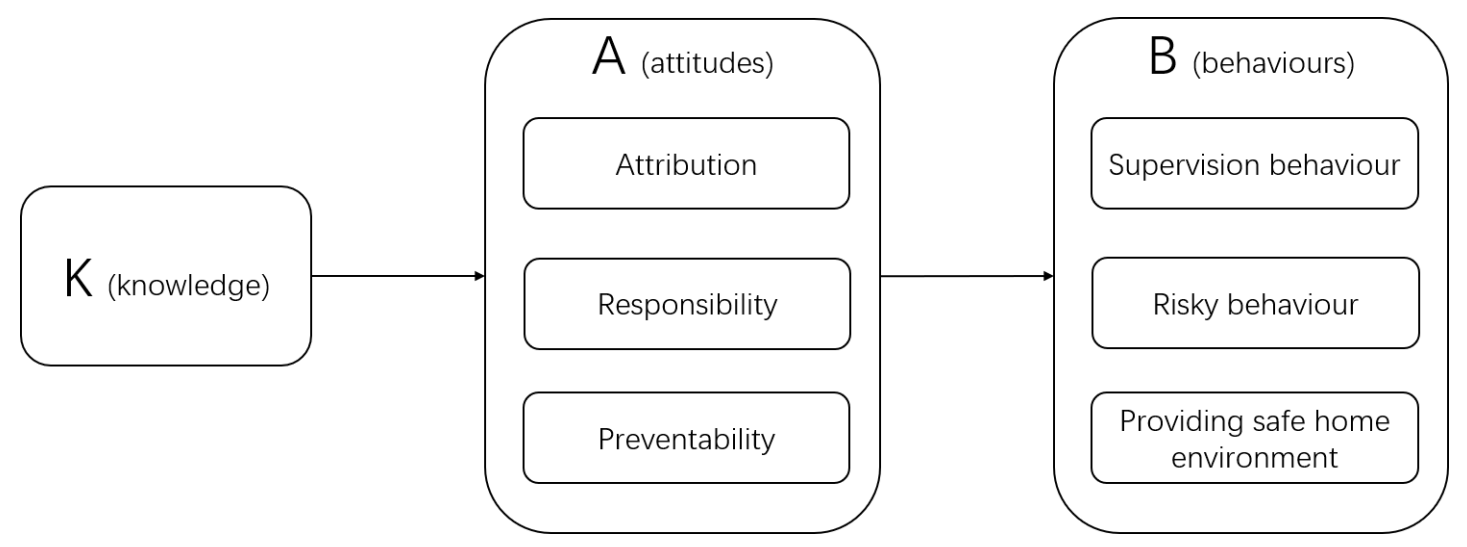

Figure 1 Theoretical framework based on KAB model in Jiading District, Shanghai, China, November 2018. KAB, knowledge, attitude and behaviour. 
reverse-scored, that is, parents had the best attitude of injury attribution if they strongly disagreed (4 on the Likert scale).

Parents' attitudes about responsibility were assessed by two statements: 'No matter who takes care of the children, parents have the primary responsibility for their children's safety' and 'Parents are primarily responsible for helping their children develop an attitude of safety'. These were all positively scored questions, that is, the more the parents agreed, the higher scores they received.

Parents' attitudes about preventability were assessed by two statements: 'Unintentional injuries are preventable' and 'There are many things parents can do to prevent unintentional injuries to their children'. These were all positively scored.

\section{Parents' behaviours}

The ultimate goal of this study was to provide a basis for developing feasible parental interventions that can be provided in community health centres. Therefore, we sought to explore parents' attitudes related to their behaviours. Focusing on child injuries in home environments, we compared three injury-preventive behaviours adopted by parents from the perspective of parental intervention. The first was providing a safe home environment. ${ }^{31}$ Owing to their physical characteristics, children are inevitably vulnerable to some form of injuries, such as falls. To prevent such injuries, parents need to make the home environment safer by removing dangerous objects (eg, pesticides) and taking protective measures, such as securing television and furniture to the walls and using outlet covers. Here, the home environment (not the child) is the direct object of parental behaviour. The second injury-preventive behaviour is not handing dangerous objects to children ${ }^{32}$; for example, a burn injury can occur if parents give their children hot water. Here, the child is the direct object, and we assume that parents do not consciously perform dangerous behaviours, but these occur because they do not understand the risks. The third injury-preventive behaviour is supervising the child continuously. ${ }^{33}$ As stated above, young children are vulnerable to injuries and it is not practical to prevent all injuries. Thus, it is necessary to supervise them continuously. This type of behaviour requires looking after the child continuously, which may be difficult because it involves considerable effort and persistence for a long time.

Each behaviour question was followed by a frequency of behaviour question that asked the respondent how often the specific condition occurred in the past 4 weeks. These were stated in the form of Likert scale responses as $1=$ never (no occurrences in the past 30 days), $2=$ rarely (1-2 times in the past 30 days), $3=$ sometimes $(3-10$ times in the past 30 days), $4=$ often ( $>10$ times in the past 30 days) and 5 =always (all the time in the past 30 days). Some questions were positively scored and some were reverse-scored (see online supplemental file).
Parents' supervision behaviours were the parental behaviours during daily supervision. There were three items about supervision behaviours: (1) 'Keeping an eye on the child without letting them out of my sight' (positively scored), (2) 'Getting people who are not yet adults to help with childcare' (reverse-scored) and (3) 'Performing other activities, such as playing on the mobile phone, while looking after the child' (reverse-scored). A higher score indicated safer behaviour.

Parents' risky behaviours were behaviours by parents that are dangerous for the child. There were four risky behaviour items, which were reverse-scored. A higher score indicated safer behaviour.

Parents' behaviours of providing a safe home environment refer to the parents providing a safe home environment to children. There were 27 questions about home environment, which were positively scored. A higher score indicated that the parents provided a safer home environment.

\section{Statistical analysis}

Analyses of the Kruskal-Wallis rank-sum test and $\chi^{2}$ test were conducted to compare correlations between KAB and respondents' demographic factors. The Spearman correlation test was used to compare correlations between knowledge, attitudes and behaviours. A confirmatory factor analysis (CFA) ensures the credibility of the questionnaire (the CFA threshold is 0.05 , or the CI covers this range). ${ }^{34}$ SEM can assess the mediation effects of multiple mediators. ${ }^{35}$ Since the current study data do not conform to normal distribution, we used the GSEM for mediation analysis ${ }^{36}$ to discover the direct and indirect relationships between variables. Analyses were performed using Stata V.14.0. Direct, indirect and total effects were reported as unstandardised beta coefficients as well as standard $95 \%$ CI, and $\mathrm{p}<0.05$ was considered statistically significant.

All respondents have understood the background, purpose and method of the study before participating, signed the informed consent form, volunteered to participate in the study, and had the right to refuse or withdraw from the study.

\section{Patient and public involvement}

Patients or the public were not involved in the design, conduct, reporting or dissemination plans of our research.

\section{RESULTS}

Demographic characteristics of the children and their parents

Table 1 shows the demographic characteristics of the children and the respondents. There were 298 (62.61\%) mothers and $188(37.39 \%)$ fathers. There were 183 $(38.45 \%)$ respondents aged $25-30$ and $147(36.55 \%)$ respondents aged 30-35. Moreover, 288 (60.50\%) respondents possessed a college degree or higher, and more than $95 \%$ of them were employed.

\section{KAB scores}

As shown in table 2, the average score of respondents' knowledge was 4.80 , and the scores for attitudes of 
Table 1 Demographic characteristics of the respondents and children and the occurrence and types of injuries in children $(\mathrm{N}=476)$

\begin{tabular}{|c|c|c|}
\hline Variable & & n (\%) \\
\hline \multirow{3}{*}{$\begin{array}{l}\text { Children's age } \\
\text { (years) }\end{array}$} & 0 & 168 (35.29) \\
\hline & 1 & 151 (31.72) \\
\hline & $2-3$ & 157 (32.98) \\
\hline \multirow{3}{*}{$\begin{array}{l}\text { Number of } \\
\text { children }\end{array}$} & 1 & $352(73.95)$ \\
\hline & 2 & $121(25.42)$ \\
\hline & $\geq 3$ & $3(0.63)$ \\
\hline \multirow[t]{2}{*}{ Respondent's sex } & Female & $298(62.61)$ \\
\hline & Male & $188(37.39)$ \\
\hline \multirow{4}{*}{$\begin{array}{l}\text { Respondent's } \\
\text { age (years) }\end{array}$} & $<25$ & $35(7.35)$ \\
\hline & $25-30$ & $183(38.45)$ \\
\hline & $31-35$ & $147(36.55)$ \\
\hline & $>35$ & $87(17.65)$ \\
\hline \multirow[t]{3}{*}{$\begin{array}{l}\text { Respondent's } \\
\text { education }\end{array}$} & $\begin{array}{l}\text { Elementary school, middle } \\
\text { school and high school }\end{array}$ & $82(17.23)$ \\
\hline & Junior college & $106(22.27)$ \\
\hline & Undergraduate and above & $288(60.50)$ \\
\hline \multirow[t]{4}{*}{$\begin{array}{l}\text { Respondent's } \\
\text { occupation }\end{array}$} & $\begin{array}{l}\text { Employees of state-owned } \\
\text { enterprises and public } \\
\text { institutions }\end{array}$ & 148 (31.09) \\
\hline & $\begin{array}{l}\text { Employees of foreign- } \\
\text { funded, private and other } \\
\text { enterprises }\end{array}$ & $228(47.90)$ \\
\hline & $\begin{array}{l}\text { Other (farmers, soldiers, } \\
\text { freelancers, etc) }\end{array}$ & $82(17.23)$ \\
\hline & Unemployed & $18(3.78)$ \\
\hline $\begin{array}{l}\text { For nearly } 6 \\
\text { months, the } \\
\text { parents and } \\
\text { children lived } \\
\text { together }\end{array}$ & No & $0(0.00)$ \\
\hline
\end{tabular}

\begin{tabular}{llc} 
& Yes & $476(100.00)$ \\
$\begin{array}{l}\text { Annual per } \\
\text { capita household } \\
\text { income (¥) }\end{array}$ & $<20000$ & $35(7.35)$ \\
& $20000-49999$ & $190(39.92)$ \\
& $50000-79999$ & $133(27.94)$ \\
\hline $\begin{array}{l}\text { Occurrence of } \\
\text { unintentional } \\
\text { injury }\end{array}$ & No 000 & $118(24.79)$ \\
\hline $\begin{array}{l}\text { Type of } \\
\text { unintentional } \\
\text { injury }\end{array}$ & Yes & $435(91.39)$ \\
& Falls & $41(8.61)$ \\
\hline
\end{tabular}

Burns 7 (17.07)

Continued

\begin{tabular}{lll}
\hline Table 1 Continued & \\
\hline Variable & $\mathbf{n ~ ( \% )}$ \\
\hline & Suffocation & $0(0)$ \\
& Drowning & $0(0)$ \\
& Other (poisoning, animal & $7(17.07)$ \\
& scratches and bites, etc) & \\
\hline
\end{tabular}

attribution, responsibility and preventability were 3.43 , 6.92 and 6.62, respectively. Each dimension of behaviours was categorised into three categories according to the scores: low, medium and high. About one-third of the respondents got high scores in terms of their behaviours.

The coefficients of internal consistency (Cronbach's $\alpha$ ) for knowledge, attitudes, supervision behaviours, risky behaviours and behaviours of providing safe home environment were $0.71,0.84,0.77,0.75$ and 0.62 , respectively. The following were the CFA results: RMSEA (Root-meansquare Error of Approximation) $=0.107,90 \%$ CI 0.0406 to 0.1920 , RMSR (Root mean square residual) $=0.0032$, TLI (Tucker-Lewis Index) $=0.9730$ and CFI (Comparative Fit Index $)=0.9955$.

\section{Univariable analysis of KAB and respondents' demographic factors}

The results of the univariable analysis showed that respondents' education level was related to knowledge, preventability and responsibility. Respondents' age was related to parental knowledge and risky behaviours, while respondents' education was related to knowledge, responsibility and risky behaviours (see table 3 ).

\section{Correlation analysis of $\mathrm{KAB}$}

The correlation analysis of KAB showed that knowledge was significantly correlated with preventability, responsibility and risky behaviours. There was significant correlation between injury attribution, responsibility, preventability, respondents' supervision behaviours, risky behaviours and home environment. Preventability was significantly correlated with responsibility, supervision, risky behaviours and home environment. Providing a safe home environment was significantly correlated with respondents' supervision behaviours and risky behaviours. There was a significant correlation between parents' supervision behaviours and risky behaviours (see table 4).

\section{Mediating role of parents' attitudes}

The significant factors in the univariable analysis and correlation analysis were incorporated into the GSEM. The results showed that child's age, respondent's sex and respondent's occupation were not significant and were therefore excluded. We also filtered the meaningless paths in the GSEM and explored the direct and indirect associations of factors on the outcome variables through each path. 
Table 2 Parents' scores on knowledge, attitudes and behaviours in Jiading District, Shanghai, China, November 2018

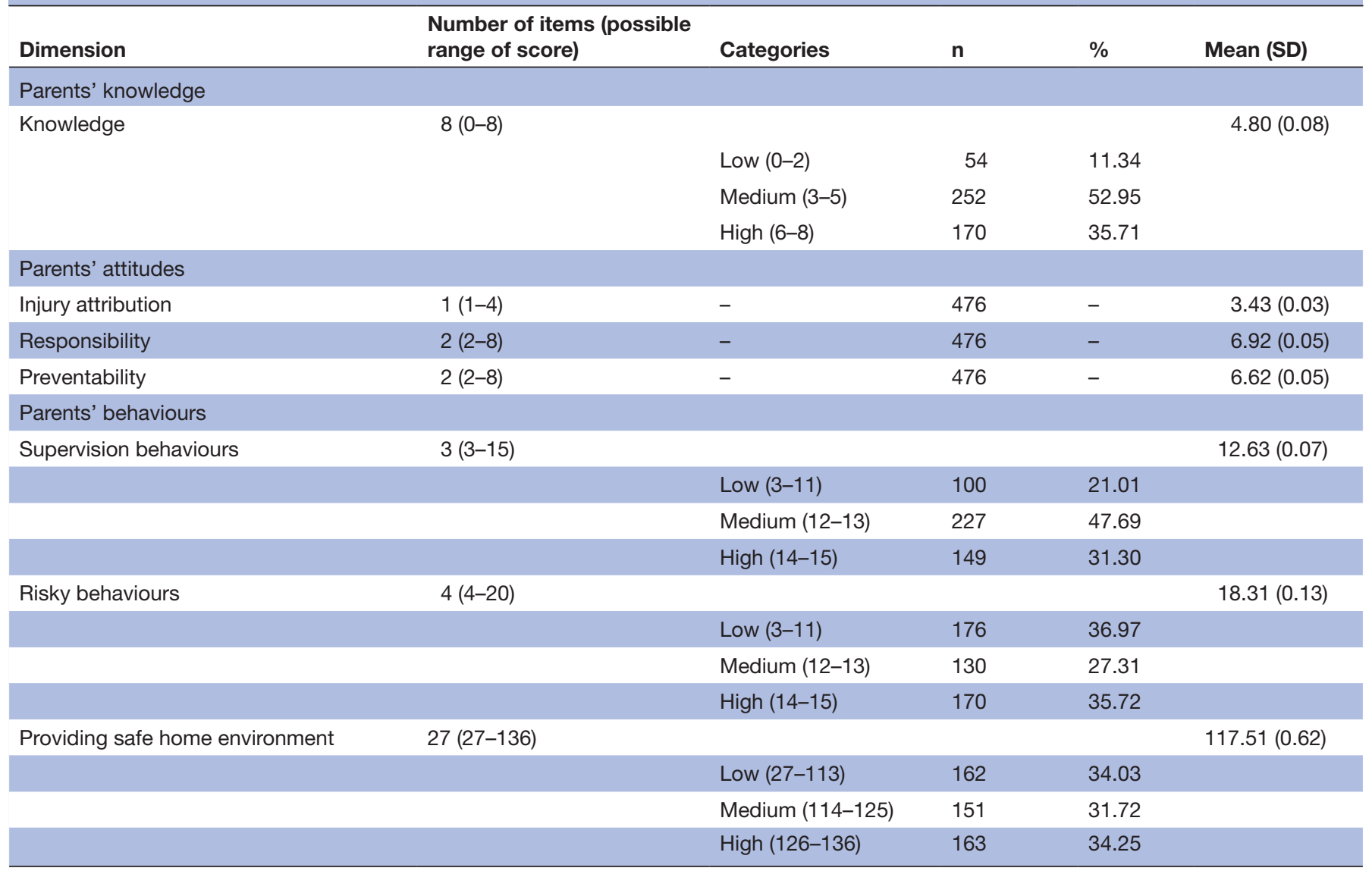

Data presented as mean (SD).

The results of the mediation analysis are reported in table 5 and figure 2 . There was a direct association between attitude of preventability and supervision behaviours $(\beta$ $0.27,95 \%$ CI 0.14 to 0.40 ), which means that the better the level of preventability, the better the supervision behaviours. The indirect factors were injury attribution $(\beta 0.74,95 \%$ CI 0.37 to 1.11$)$ and responsibility $(\beta 0.46$,
$95 \%$ CI 0.23 to 0.69$)$. The factors directly associated with risky behaviours were knowledge ( $\beta 0.19,95 \%$ CI 0.13 to $0.24)$ and injury attribution ( $\beta 0.37,95 \%$ CI 0.21 to 0.54 ), while the factor indirectly associated was respondent's education ( $\beta 0.14,95 \%$ CI 0.09 to 0.18$)$. The factor directly associated with home environment was preventability ( $\beta$ $0.33,95 \%$ CI 0.20 to 0.46 ), and the indirect factors were

Table 3 Univariable analysis of knowledge, attitude and behaviour and respondents' demographic factors in Jiading District, Shanghai, China, November 2018

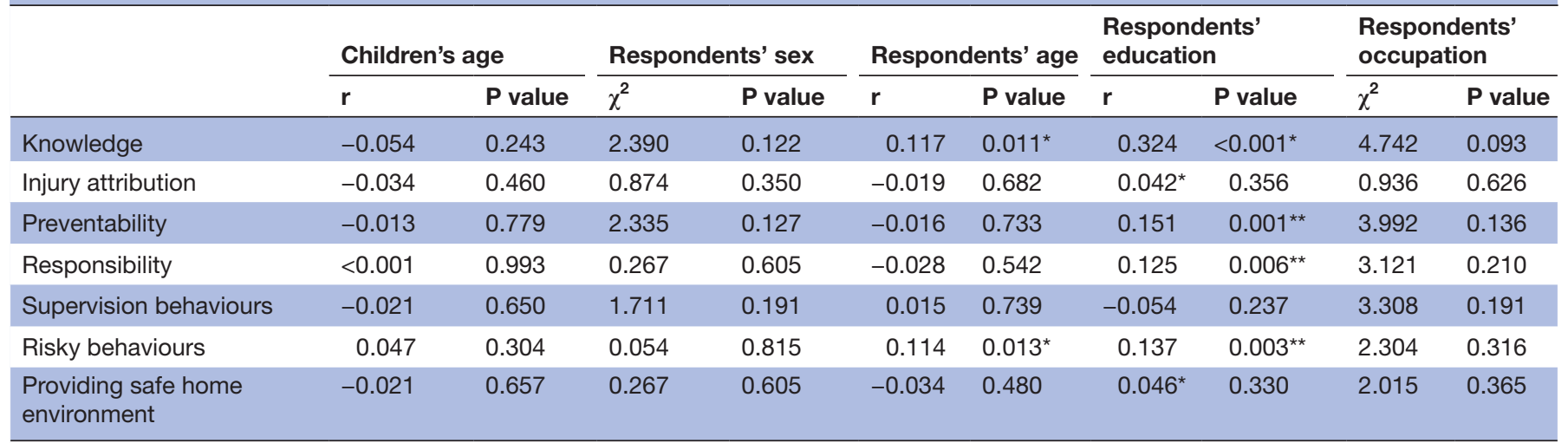

$r$ is the value of Kruskal-Wallis rank-sum test.

Since the number of children and type of injury were not found to be correlated with other variables, they were not shown.

${ }^{*} \mathrm{P}<0.05,{ }^{* *} \mathrm{P}<0.01$ 
Table 4 Spearman correlation coefficient of knowledge, attitude and behaviour in Jiading District, Shanghai, China, November 2018

\begin{tabular}{|c|c|c|c|c|c|c|}
\hline & Knowledge & Injury attribution & Preventability & Responsibility & Supervision & Risky behaviours \\
\hline Injury attribution & 0.066 & & & & & \\
\hline Responsibility & $0.133^{\star}$ & $0.363^{*}$ & $0.691^{*}$ & & & \\
\hline Supervision behaviours & 0.007 & $0.125^{\star}$ & $0.194^{*}$ & $0.188^{*}$ & & \\
\hline
\end{tabular}

${ }^{*} \mathrm{P}<0.05$.

knowledge ( $\beta 0.07,95 \%$ CI 0.03 to 0.10$)$, injury attribution $(\beta 0.92,95 \%$ CI 0.54 to 1.30$)$ and responsibility $(\beta$ $0.57,95 \%$ CI 0.34 to 0.80$)$. In addition, the factors directly associated with occurrence of injury were providing a safe home environment $(\beta-0.41,95 \% \mathrm{CI}-0.82$ to -0.01$)$ and children's age ( $\beta 0.44,95 \%$ CI 0.03 to 0.84$)$.

\section{DISCUSSION}

To the best of our knowledge, this is the first study to analyse the different mediating roles of parental attitudes between parental knowledge and different parental behaviours related to unintentional injuries at home in children aged $0-3$.

Findings of this study supported the view that safety knowledge possessed by parents played different roles in parental supervision behaviours, risky behaviours and providing safe home environment.

In addition, home environment was related to child injuries, which is consistent with findings from other studies. ${ }^{6}$ However, neither supervision behaviour nor risky behaviour was associated with the occurrence of injuries in children, which may be because children are younger

Table 5 Direct, indirect and total effects on behaviours in Jiading District, Shanghai, China, November 2018

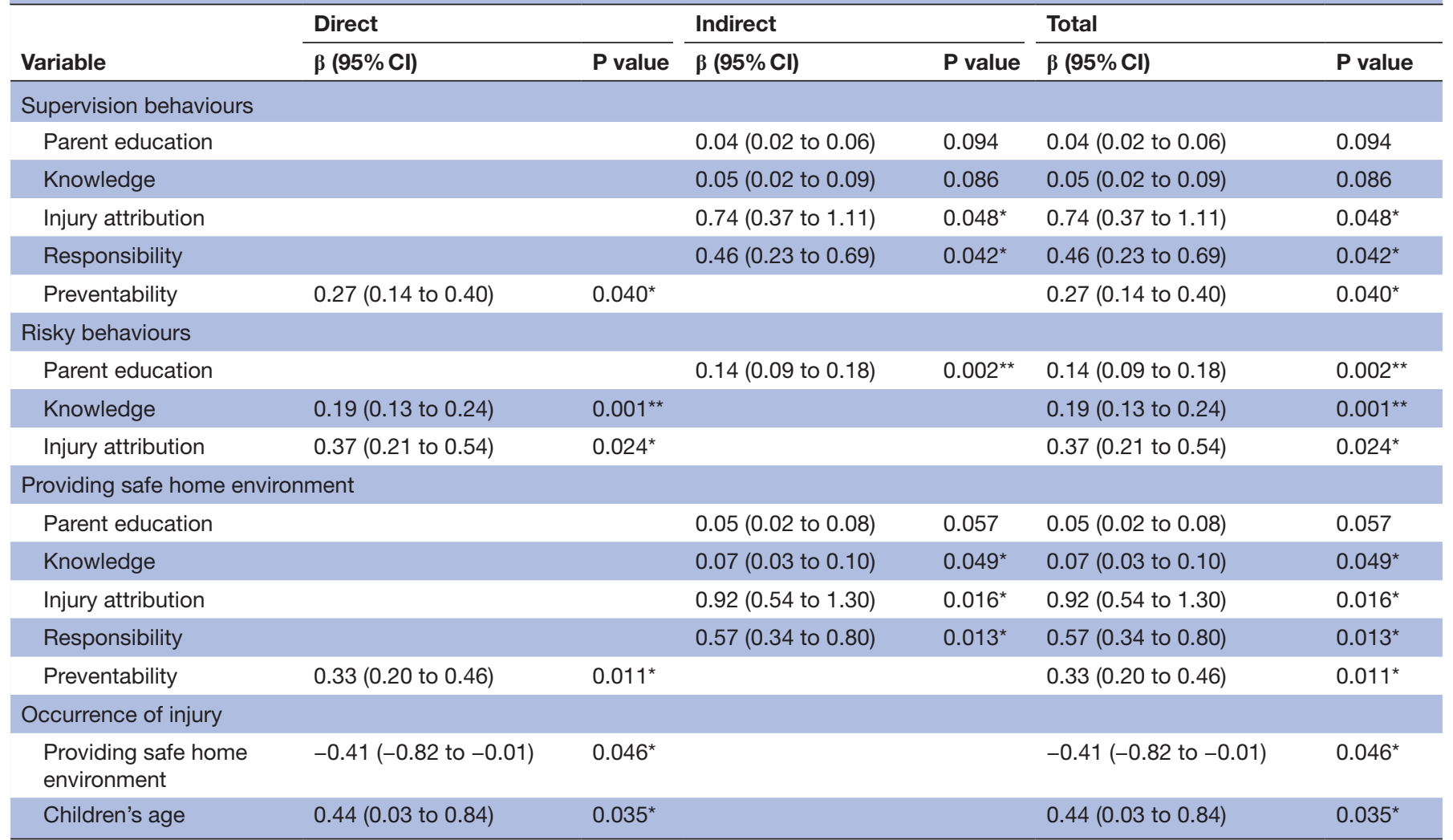

The models were adjusted for sociodemographic variables (child age, child sex, number of children, respondents' sex, respondents' age, respondents' education and respondents' occupation) and only those with $\mathrm{p}<0.1$ were displayed in the results. Model fit indices: AIC (Akaike information criterion): 4611.033; BIC (Bayesian Information Criterions): 4731.647.

${ }^{*} \mathrm{P}<0.05,{ }^{* *} \mathrm{P}<0.01$. 


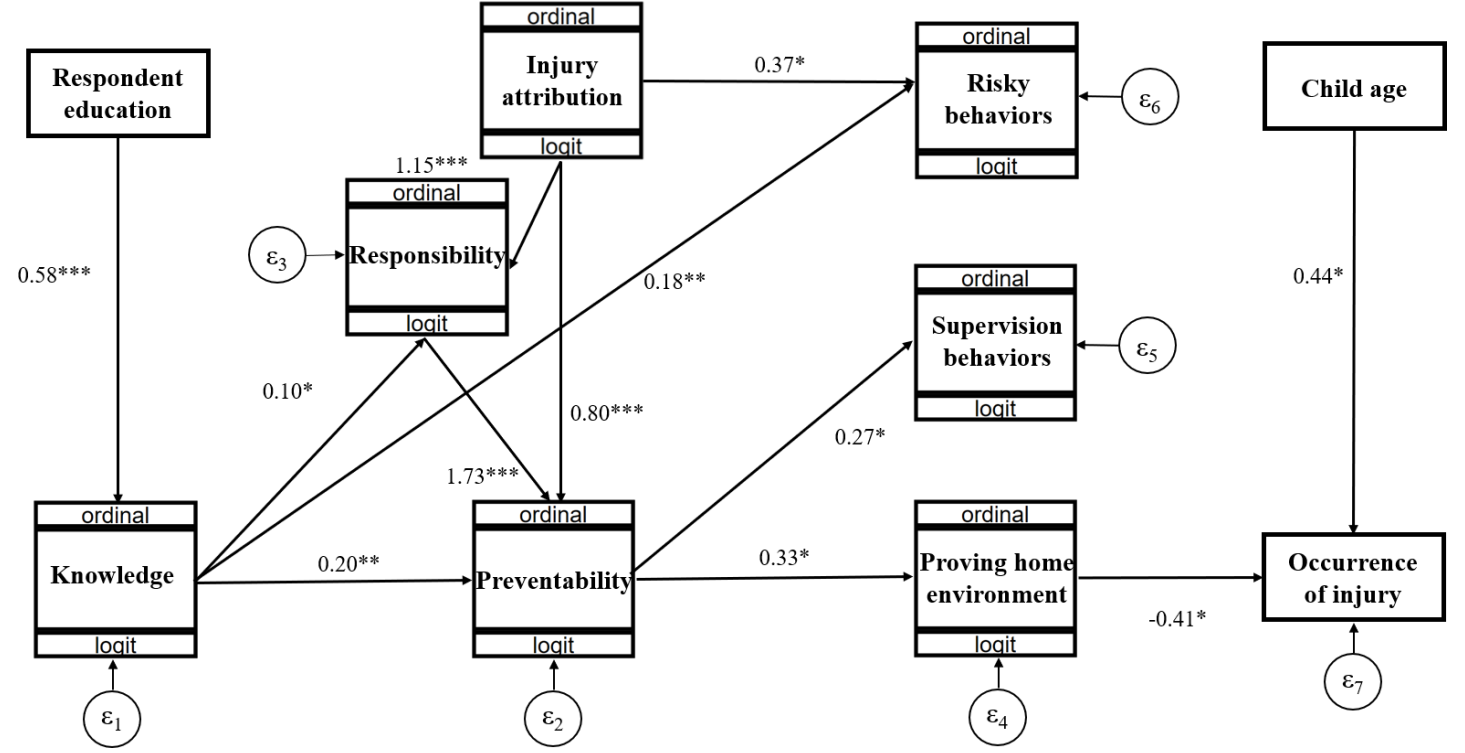

Figure 2 A mediation analysis model showing KAB's hypothesised path (final model) in Jiading District, Shanghai, China, November 2018. The coefficient is the value of $\beta$. ${ }^{\star} \mathrm{P}<0.05,{ }^{\star \star} \mathrm{P}<0.01,{ }^{\star \star \star} \mathrm{P}<0.001$. KAB, knowledge, attitude and behaviour.

and the incidence of injury is lower. Further, in contrast to a Canadian study of children's outdoor injuries, children aged 0-3 years spent most of their time at home, where the environment could be transformed, unlike outdoor environments which are difficult to change. The possibility of injuries can only be reduced when parents increase their level of supervision and reduce children's risky behaviours.

Through mediation analysis, we found there were direct associations between knowledge and risky behaviour, which means parents with safety knowledge can avoid dangerous behaviours. A previous intervention study focusing on school-aged children in China also confirmed that knowledge education can reduce parents' risky behaviours. ${ }^{37}$ Furthermore, our research found that parents with better knowledge do not directly associate with parents' supervision behaviours and providing safe home environment. However, knowledge could indirectly associate with behaviours through attitudes as mediating roles.

The findings of this study also showed that attitudes have direct associations with different behaviours. Furthermore, different attitudes play different mediating roles between knowledge and behaviours. Attitude of injury attribution has a direct association with risky behaviours. The more parents notice that the occurrence of unintentional injury cannot be attributed to bad luck, the more they will actively avoid risky behaviours. Attitude of preventability has a direct association with providing a safe home environment and supervision behaviours. Research in Iran showed that attitude of preventability could improve the supervision behaviours of children's mothers and even protect children. ${ }^{38}$ If the parents do not previously realise the importance of injury, this will affect their motivation to participate and change their behaviour. ${ }^{39} \mathrm{~A}$ previous study also suggested attitude is associated with the behaviour of children's mothers. ${ }^{40}$ That is, the better the attitude of preventability that parents have, the better the level of behaviour adopted. In addition, our research found that attitude is also an important mediating factor. Knowledge, injury attribution and responsibility have been associated with home environment and supervision behaviours through preventability. In a randomised controlled experiment in Canada, it was also found that parents' supervision behaviour was significantly better than that of the control group after the intervention aimed at improving the level of parents' preventability of children's unintentional injuries. ${ }^{41}$

According to the research results, it can be found that parents' knowledge and attitudes play important roles in providing a safe home environment, which is directly related to child injuries at home. This study also found that there is no significant relationship between children's age and parents' knowledge and attitude. That is, with the growth of children's age, parents' knowledge and safety attitude did not improve, which suggests further intervention is needed to improve knowledge and safety attitudes. In the GSEM, although the indirect association between knowledge and supervision behaviour is not statistically significant, to some extent it can be considered that it is possible to improve behaviours by influencing attitude through improving the knowledge level. In addition to the regular assessment of children's home environments as mentioned in previous studies and guidance for parents, ${ }^{42}$ community child healthcare providers should also develop health education interventions to improve parents' knowledge and attitudes towards different parental behaviours. Interventions to enhance safety knowledge fall into the following three categories: (1) knowledge of risky behaviours, such as knowing that it is dangerous to sleep beside a child on the same bed; (2) operational knowledge, such as knowledge of first 
aid measures after burns; and (3) basic knowledge, such as knowing that injuries mainly occur at home and the leading cause of death of children is unintentional injury.

The results suggest that our work should be further examined in combination with different explanatory factors in different ways. In China, community-based basic public services with wide coverage have been fully implemented, ${ }^{43}$ and the community will provide 'health management services for children aged $0-6,{ }^{, 4}$ Although there has been an official platform, the intervention content provided by the community childcare doctors toparents is not targeted to improve parents' knowledge, attitude and behaviors. Policymakers should develop appropriate intervention manuals and intervention packages to include child unintentional injuries in the intervention packages for use by clinicians. In view of parents whose attitude levels need further improvement, safety education should be strengthened, providing home safety education that can create a safer home environment, ${ }^{45}$ and community clinicians need to intervene with parents using an intervention package. The intensity of educational interventions varies between studies, ${ }^{46}$ and the results and costs are often different. There is no need for a complicated intervention if simple interventions (such as easy knowledge and skills dissemination) are efficient.

Our study also has several limitations. First, we employed a cross-sectional design; therefore, we cannot draw any causal inferences from the results. Second, the questionnaires were filled by parents, who may have deliberately withheld some information, especially about their attitudes and behaviours, which could have led to a social desirability bias and lack of validity of the findings. Finally, the present study was only conducted in Jiading District in Shanghai, which is an economically developed area; therefore, these results cannot be freely extended to other areas and the findings have limited generalisability.

Finally, for researchers, a longitudinal study is needed. In addition, we suggest that researchers further develop a widely applicable, psychometrically reliable and valid scale for assessing parents' safety literacy covering knowledge, attitudes and behaviours to guide feasible community health intervention to prevent unintentional injuries in children.

\section{CONCLUSIONS}

The findings of this study confirm that attitudes play different mediating roles between knowledge and different behaviours. An important practical implication is that parents' attitudes, especially towards preventability and responsibility, need to be considered when developing health education programmes to improve parental supervision behaviours and provide a safe home environment for children.

\section{Author affiliations}

${ }^{1}$ School of Public Health, Fudan University, Shanghai, China

${ }^{2}$ China Research Center on Disability, Fudan University, Shanghai, China
${ }^{3}$ School of Community and Environmental Health, Old Dominion University, Norfolk, Virginia, USA

${ }^{4}$ Preventive Health Department, Community Health Centre of Jiading Town,

Shanghai, China

${ }^{5}$ Chronic Disease Prevention and Control Department, Changning District Center for Disease Control and Prevention, Shanghai, China

${ }^{6}$ Department of Neurosurgery, Children's Hospital of Fudan University, Shanghai, China

Acknowledgements We are grateful to the staff at the community health centres. We would also like to thank all the residents for their participation. We would like to thank Editage (www.editage.cn) for English language editing.

Contributors XL contributed to conception and design of the study, with assistance from XM and JL. XM drafted the manuscript, while QZ, RJ, HW, QX, JZ, WD and $\mathrm{FC}$ contributed to revision of the manuscript. XM finalised the manuscript. $\mathrm{XL}$ and $\mathrm{XM}$ contributed to statistics. And XL responsibled for the overall content as the guarantor. All authors have read and approved the final manuscript.

Funding The project was supported by the National Natural Science Foundation of China (no. 71974037, 71573049), the National Social Science Foundation of China (no. 17ZDA078) and the 111 Project (grant no. B16031).

Disclaimer The funders had no role in study design, data collection and analysis, decision to publish or preparation of the manuscript.

Competing interests None declared.

Patient consent for publication Obtained.

Ethics approval This study involves human participants and was approved by the Medical Research Ethics Committee, School of Public Health, Fudan University (IRB no. 2018-01-663). Participants gave informed consent to participate in the study before taking part.

Provenance and peer review Not commissioned; externally peer reviewed. Data availability statement Data are available upon reasonable request.

Supplemental material This content has been supplied by the author(s). It has not been vetted by BMJ Publishing Group Limited (BMJ) and may not have been peer-reviewed. Any opinions or recommendations discussed are solely those of the author(s) and are not endorsed by BMJ. BMJ disclaims all liability and responsibility arising from any reliance placed on the content. Where the content includes any translated material, BMJ does not warrant the accuracy and reliability of the translations (including but not limited to local regulations, clinical guidelines, terminology, drug names and drug dosages), and is not responsible for any error and/or omissions arising from translation and adaptation or otherwise.

Open access This is an open access article distributed in accordance with the Creative Commons Attribution Non Commercial (CC BY-NC 4.0) license, which permits others to distribute, remix, adapt, build upon this work non-commercially, and license their derivative works on different terms, provided the original work is properly cited, appropriate credit is given, any changes made indicated, and the use is non-commercial. See: http://creativecommons.org/licenses/by-nc/4.0/.

\section{ORCID iDs}

Qi Zhang http://orcid.org/0000-0002-4546-0620

Xiaohong Li http://orcid.org/0000-0002-8618-5549

\section{REFERENCES}

1 World Health Organization. World report on child injury prevention. Geneva: WHO, 2008.

2 Alonso-Fernández N, Jiménez-García R, Alonso-Fernández L, et al. Unintentional injuries and associated factors among children and adolescents. An analysis of the Spanish National health survey. Int $J$ Public Health 2017;62:961-9.

3 Mack KA, Rudd RA, Mickalide AD, et al. Fatal unintentional injuries in the home in the U.S., 2000-2008. Am J Prev Med 2013;44:239-46.

4 Khambalia A, Joshi P, Brussoni M, et al. Risk factors for unintentional injuries due to falls in children aged 0-6 years: a systematic review. Inj Prev 2006;12:378-81.

5 Schnitzer PG, Dowd MD, Kruse RL, et al. Supervision and risk of unintentional injury in young children. Inj Prev 2015;21:e63-70.

.


6 Shields W, McDonald E, Frattaroli S, et al. Structural housing elements associated with home injuries in children. Inj Prev 2016;22:105-9.

7 Hubbard S, Cooper N, Kendrick D, et al. Network meta-analysis to evaluate the effectiveness of interventions to prevent falls in children under age 5 years. Inj Prev 2015;21:98-108.

8 Barat A, Watson MC, Mulvaney CA. Preventing unintentional home injuries among children: exploring the perceptions of Iranian health professionals. Prim Health Care Res Dev 2019;20:1-7.

9 Turner S, Arthur G, Lyons RA. Modification of the home environment for the reduction of injuries. Cochrane Database Syst Rev 2010;2:899-928.

10 Jones VC, Shields W, Ayyagari R, Vanya C, Jones W, et al. Association between unintentional child injury in the home and parental implementation of modifications for safety. JAMA Pediatr 2018;172:1189-90.

11 Morrongiello BA, House K. Measuring parent attributes and supervision behaviors relevant to child injury risk: examining the usefulness of questionnaire measures. Inj Prev 2004;10:114-8.

12 Huynh HT, Demeter NE, Burke RV, et al. The role of adult perceptions and supervision behavior in preventing child injury. $J$ Community Health 2017;42:649-55.

13 Ning P, Cheng P, Schwebel DC, et al. An App-Based intervention for caregivers to prevent unintentional injury among preschoolers: cluster randomized controlled trial. JMIR Mhealth Uhealth 2019;7:e13519.

14 Mackay JM. 28 safe medicine storage: a look at the disconnect between parent knowledge and behaviour. Inj Prev 2017;23:A11::1-11.

15 Azar ST, Miller EA, Stevenson MT, et al. Social cognition, child neglect, and child injury risk: the contribution of maternal social information processing to maladaptive injury prevention beliefs within a high-risk sample. J Pediatr Psychol 2017;42:759-67.

16 Olsen LL, Ishikawa T, Mâsse LC, et al. Risk engagement and protection survey (REPS): developing and validating a survey tool on fathers' attitudes towards child injury protection and risk engagement. Inj Prev 2018;24:106-12.

17 Frank C. The Influence of Parent Awareness of Successful Reading Strategies and the Impact on Children's Reading Behaviour and Attitude. Grade 2001:1-45.

18 Haddon W. A logical framework for categorizing highway safety phenomena and activity. J Trauma 1972;12:193-207.

19 Gong D, Yuan H, Zhang Y, et al. Hypertension-Related knowledge, attitudes, and behaviors among Community-Dwellers at risk for high blood pressure in Shanghai, China. Int J Environ Res Public Health 2020;17:3683.

$20 \mathrm{Kemm}$ J, Close A. Health promotion. Theory \& practice 1995.

21 National bureau of statistics of China. China statistical yearbook 2018. Beijing: China Statistics Press, 2018.

22 Shanghai statistics bureau. Shanghai statistical yearbook 2018. Beijing: China Statistics Press, 2018.

23 Kline RB. How to fool yourself with SEM. principles and practice of structural equation modeling, 2005.

24 World Health Organization. International Statistical Classification of Diseases and Related Health Problems 10th Revision (ICD-10)-WHO Version for 2016, 2016. Available: https://icd.who.int/browse10/2016/ en\#/W00-X59

25 American Academy of Pediatrics. Caring for your baby and young child. 6th Edn. Bantam, 2014.

26 Alexander K, Lightman N. Injury prevention during childhood, 2014

27 Speltz ML, Gonzales N, Sulzbacher S, et al. Assessment of injury risk in young children: a preliminary study of the injury behavior checklist. J Pediatr Psychol 1990;15:373-83.
28 Yang J, Lee SY, Zhou Y. Parent supervision attributes profile questionnaire (PSAPQ) for young children: psychometric properties of the Chinese version. BMC Public Health 1944;19.

$29 \mathrm{Ng} \mathrm{TWH}$, Sorensen KL, Eby LT, Ng T, Eby S. Locus of control at work: a meta-analysis. J Organ Behav 2006;27:1057-87.

30 Caprara GV, Barbaranelli C, Borgogni L, et al. The "big five questionnaire": A new questionnaire to assess the five factor model. Pers Individ Dif 1993;15:281-8.

31 Keall MD, Pierse N, Howden-Chapman P, et al. Home modifications to reduce injuries from falls in the home injury prevention intervention (HIPI) study: a cluster-randomised controlled trial. Lancet 2015;385:231-8.

32 Tsoumakas K, Dousis E, Mavridi F, et al. Parent's adherence to children's home-accident preventive measures. Int Nurs Rev 2009;56:369-74.

33 Sethi D, Towner E, Vincenten J. European report on child injuries prevention. , 2008: 16, 5-6.

34 Stanislav K. Confirmatory factor analysis using confa. The Stata Journal 2009;9:329-73.

35 VanderWeele TJ. Mediation analysis: a practitioner's guide. Annu Rev Public Health 2016;37:17-32.

36 Fisher ZF, Bollen KA. An instrumental variable estimator for mixed indicators: Analytic derivatives and alternative Parameterizations. Psychometrika 2020;85:660-83.

37 Ning P, Cheng P, Schwebel DC, et al. An App-Based intervention for caregivers to prevent unintentional injury among preschoolers: cluster randomized controlled trial. JMIR Mhealth Uhealth 2019;7:e13519.

38 Poorolajal J, Cheraghi P, Hazavehei SMM, et al. Factors associated with mothers' beliefs and practices concerning injury prevention in under five-year children, based on health belief model. $J$ Res Health Sci 2012;13:63.

39 Machin Al, Ngamsuoy A, Pearson P. Collaborative child home injury prevention in Thailand: an action research study. Nurs Health Sci 2018;20:206-13.

40 Poorolajal J, Cheraghi P, Hazavehei SMM, et al. Factors associated with mothers' beliefs and practices concerning injury prevention in under five-year children, based on health belief model. J Res Health Sci 2012;13:63-8.

41 Morrongiello BA, Sandomierski M, Zdzieborski D, et al. A randomized controlled trial evaluating the impact of the Supervising for home safety program on parent appraisals of injury risk and need to actively supervise. Health Psychol 2012;31:601-11

42 Qiu X, Wacharasin C, Deoisres W, et al. Characteristics and predictors of home injury hazards among toddlers in Wenzhou, China: a community-based cross-sectional study. BMC Public Health 2014:14:638.

43 Chen Z. Launch of the health-care reform plan in China. Lancet 2009:373:1322-4.

44 Luo Z, Ma Y, Ke N, et al. The association between the supply and utilization of community-based primary care and child health in a context of hospital-oriented healthcare system in urban districts of Guangdong, China: a panel dataset, 2014-2016. BMC Health Serv Res 2020;20:313.

45 Kendrick D, Barlow J, Hampshire A, et al. Parenting interventions and the prevention of unintentional injuries in childhood: systematic review and meta-analysis. Child Care Health Dev 2008;34:682-95.

46 Hubbard S, Cooper N, Kendrick D, et al. Network meta-analysis to evaluate the effectiveness of interventions to prevent falls in children under age 5 years. Inj Prev 2015;21:98-108. 